\title{
EXPERIMENTAL RESEARCH REGARDING INFLUENCE OF SOIL ELECTRODE CONDUCTIVITY AND PH DATA ON PRODUCTIVITY OF AGRICULTURAL CEREAL CROPS
}

\author{
Iulian Voicea, Dragos Dumitru, Valentin Vladut \\ National Institute of Research-Development for Machines and Installations \\ Designed to Agriculture and Food Industry, Romania \\ voicea_iulian@yahoo.com, valentin_vladut@yahoo.com
}

\begin{abstract}
Within the article, an analysis of the influence of the experimental data of EC and ph of the soil on the productivity of the cereal crop is performed. The EC and PH data of the soil were collected with the help of specialized tractable equipment, and the productivity data were recorded with the help of a special device mounted on the harvester. For the measurement of soil salinity and implicitly of the above-mentioned soil electro-conductivities, the measurement of the apparent electro-conductivity of the soil (EC) by measuring the electrical resistivity and the electromagnetic behavior is regarded as the most appropriate way of establishing the spatial distribution of salinity at the surface of the ground, or deeper. Measurement of the apparent soil electrical conductivity (EC) by measuring the electrical resistivity and the electromagnetic behavior (EM) is of maximum interest for precision agriculture, as it is a safe and accurate method, which allows relatively simple data to be obtained with a large volume of measured data. Measuring soil $\mathrm{pH}$ can help to better understand nutrient availability, soil permeability and the types of cereal varieties that can be grown in Romania.
\end{abstract}

Keywords: EC, pH, soil, productivity, cereal crops.

\section{Introduction}

Precision agriculture is an innovative type of agriculture, based on new technologies, which aims to streamline the agricultural process. Through the new systems, farmers can have a greater degree of control over the whole agricultural process because they have access to new tools and precise measurements. In recent years, precision agriculture has been gaining in popularity thanks to the many benefits it offers to farmers, with new technologies becoming a separate sector of the agricultural economy, [1-3]. Just 50 years ago, farmers were still using horse-drawn carts and methods we consider obsolete today. At present, modern tractors and combines are increasingly common, and in some countries it is not excluded to even see drones flying over agricultural land and sending real-time information on crop status. Modern agriculture, also called Agriculture 4.0, presents us with a completely new approach to what we knew just a decade ago. Due to this, farm management becomes more precise and economical, while maintaining its simplicity.

Although the concept is relatively new in Romania, the beginnings of precision agriculture took place in 1970, when European farmers introduced the technique of "self-orientation" initially used on a small scale. Only in the last 15 years have reliable technologies emerged that influenced the automation of agriculture and led to the creation of precision agriculture as we know it today. First of all, we can track the position of agricultural machinery using GPS and GNSS satellite systems. We can also have access to the detailed weather forecast, carefully weigh fertilizer quantities and constantly monitor crop conditions, [4-6]. The automation of agriculture has led to the collection and processing of many types of data, the creation of topographic maps, the exact tracking of the state of the soil and of the crops for a precise seeding, but also the application of the correct quantity of fertilizer. Among the objectives of precision agriculture are: optimization of costs, increase of farm profit, as well as efficiency of all resources allocated and used. To choose the right cultivation techniques, you need to know your own soil very well. Therefore, before implementing any precision agricultural technology, it is necessary to perform soil tests. The first step is to measure the surface using a GPS system or other software based on a satellite system. This solution allows the field to be divided into smaller fragments (plots) $[7 ; 8]$. The soil type can be examined by satellite, but to obtain a complete picture of its condition, it is necessary to take soil samples from each plot or to obtain valid results with the help of agricultural equipment specially designed for this purpose. Starting from this, the mapping of the virtual soil profile using the electrical conductivity (EC) and the ph was developed to identify the surfaces with contrasting properties of the soil.

Soil electro-conductivity (EC) is one of the simplest and least expensive determinations for precision agriculture that can be made today. Soil electro-conductivity (EC) is a measurement that 
integrates many soil properties that affect the productivity of agricultural crops. These include water content, soil texture, soil organic matter (OM), depth to clay layer, cation exchange capacity (CEC), salinity. Electro-conductivity (EC) measurements of the soil can add value to agricultural operations if they can be used to help explain the variations in agricultural production. This increased understanding should then lead to improved management opportunities that either reduce input costs or accurately predict the benefits that can be gained from soil, irrigation or other land improvement, $[9,10]$. As a result, farmers who practice precision agriculture can now gather much more detailed information about the spatial characteristics of agricultural operations than they had until now.

Soil pH is a very important element that needs to be known and monitored because it is involved in many physico-chemical and biological mechanisms in the soil. The $\mathrm{pH}$ is determined either in a soil suspension in water or in a soil suspension in hydrochloric acid solution, the latter being smaller than that in the aqueous suspension by about 0.5 units. Soil classification by $\mathrm{pH}$ (in water) are - strongly acidic $\mathrm{pH}<5$, moderately acidic $\mathrm{pH}-5.01-5.80$, weakly acidic $-\mathrm{pH}-5.81-6.80$, neutral $-\mathrm{pH}-6.81-$ 7.20 , weak alkaline $-\mathrm{pH}-7.21-8.40$, strongly alkaline $-\mathrm{pH}>8.40$. Thus, on a global level, there are a number of major challenges regarding the development of national and international policies, which support the emergence of increasingly sustainable forms of land use and of obtaining an efficient agricultural production, both in industrialized and in developing countries. Obtaining good soil quality is a complex process, which depends on several factors, $[11,12]$. Therefore, it is necessary to find other soil characteristics related to its quality, but which will be easier to measure. This need to obtain increasingly complex soil quality indicators is a real concern, starting from the local level to a global one. Therefore, it is necessary to define a precise strategy, from obtaining the data from the field and until validating them, to allow the proposal of new indicators.

\section{Materials and method}

For the experimental EC and Ph soil tests, the Veris 3150 MSP mobile system was used, consisting of the module for determining soil electro-conductivity and the module for determining soil $\mathrm{pH}$. The module for determining the electrode conductivity of the soil consists of 6 disk electrodes for measuring EC (front of the platform), and the EC measurement is done by inserting these electrode discs into the soil at a depth of $2.5-5 \mathrm{~cm}$. While the frame is displaced along the ground, one pair of electrodes transmits electrical current to the ground, while another 2 pairs of electrodes measure the voltage drop. At the back of the platform we have the device for measuring the $\mathrm{pH}$ of the soil composed of 2 ph electrodes, washing system, basin and pumps, sampling system, command and control system.

The tests for the determination of the soil EC using the VERIS 3150 mobile platform were carried out within an agricultural area within the INMA Bucharest (1 hectare), on the type of BROWN REDDISH FROM THE FOREST this being processed conventionally (plowing + discussion) and sowing with wheat variety CXV that is being approved.
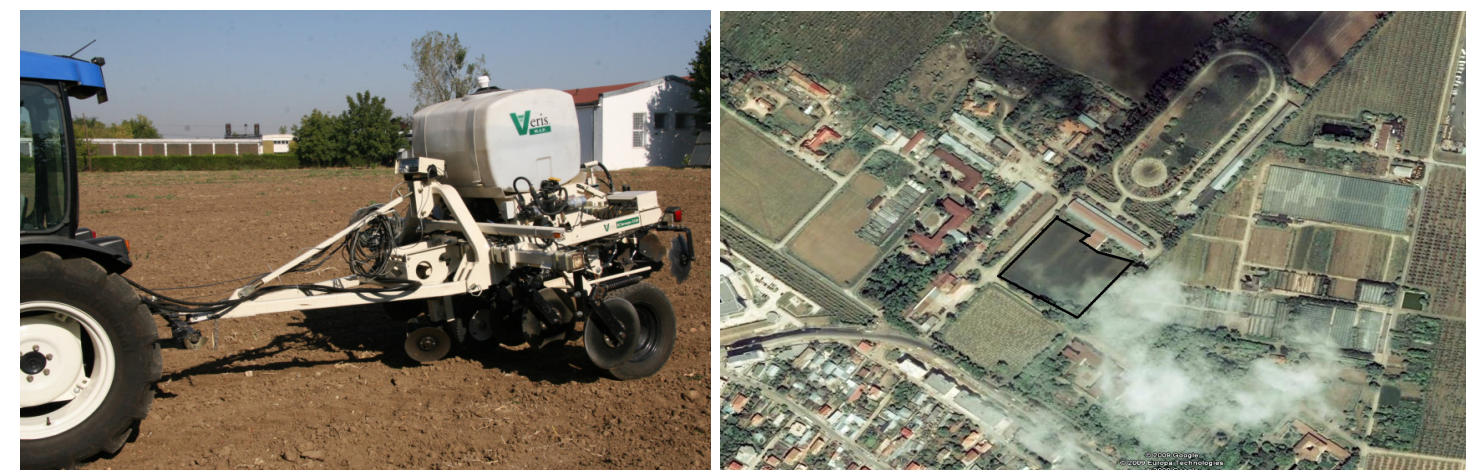

Fig. 1. System for mapping the electro-conductivity of the Veris 3150 soil with the electroconductivity (center) and ph (rear) sensors

The measurement of wheat production (CXV variety) was determined with the help of a MICROTRACK monitoring system equipped with a flow sensor mounted on the top of the tiered grain elevator of a John Deere agricultural combine. 
Micro-Trak's Grain-Trak system uses a force transducer to measure the grain flow existing in the tiled/clean grain elevator. These ,measuring fingers” are located in the way of cereals at the exit of the elevator. When passing the cereals over the fingers, they are pushed. The force created is transformed into an electrical signal by a translator. Like the other systems, this signal (voltage) is sent to the monitor and combined with the information of the humidity sensor performs a production measurement.
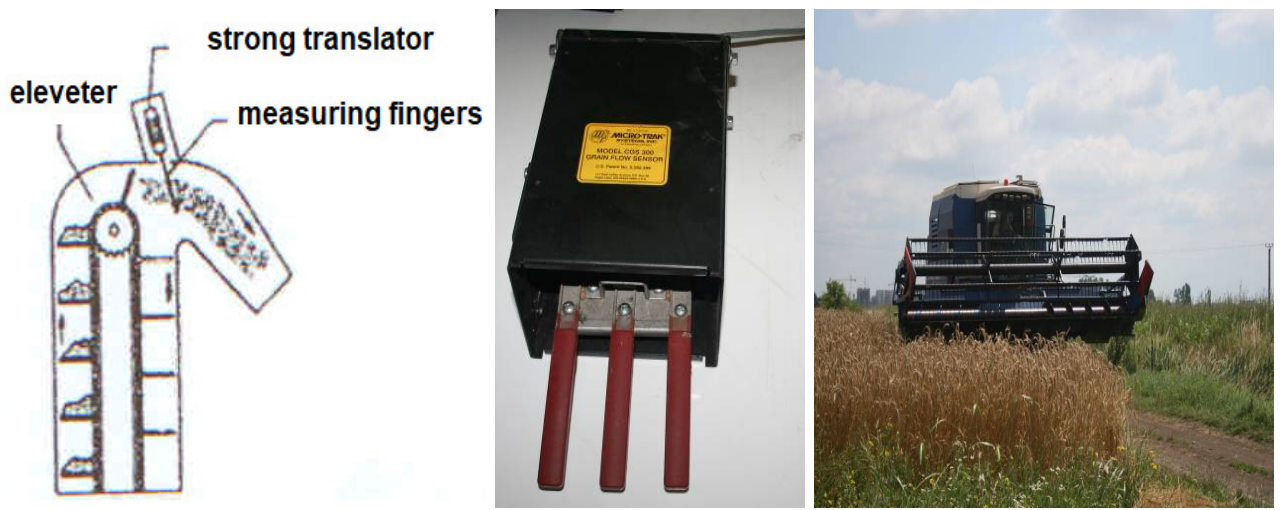

Fig. 2. System Micro-Trak Grain-Trak

\section{Results and discussion}

The measurement of the surface EC, depth EC and soil ph was performed at the end of March 2019. The data obtained using the Veris 3150 MSP system are in the form of ASCI files, which have been converted into excel files for their processing. Following the entire surface of the plot $\left(10000 \mathrm{~m}^{2}\right)$ using the VERIS 3150 platform with a tractor speed between $8-14 \mathrm{~km} \cdot \mathrm{h}^{-1}$, a number of 955 rows of data on EC, ph of the soil analyzed and cultivated with a variety were obtained of new wheat undergoing experimental testing.

Examples of raw EC/pH data obtained are presented in the table below where the obtained $\mathrm{kg} \cdot \mathrm{m}^{-2}$ productivity data were integrated.

EC data, Ph, soil productivity Brown Reddish from the forest

\begin{tabular}{|c|c|c|c|c|c|c|}
\hline $\begin{array}{c}\text { Longitude } \\
\text { degrees }\end{array}$ & $\begin{array}{c}\text { Latitude } \\
\text { degrees }\end{array}$ & $\begin{array}{c}\text { EC }_{\text {SURFACE }} \\
\mathbf{m S} \cdot \mathbf{m}^{-1}\end{array}$ & $\begin{array}{c}\mathbf{E C}_{\text {DEPTH }} \\
\mathbf{m S} \cdot \mathbf{m}^{-1}\end{array}$ & pH & $\begin{array}{c}\text { Yield } \\
\mathbf{k g} \cdot \mathrm{m}^{-2}\end{array}$ & $\underset{\mathbf{m}}{\text { Altitude, }}$ \\
\hline 26.071053 & 44.500629 & 8.2 & 9.8 & 6.8 & 0.36 & 99.900 \\
\hline 26.071056 & 44.500641 & 9.3 & 47.4 & 7.2 & 0.41 & 99.850 \\
\hline 26.071064 & 44.500648 & 9.4 & 8.5 & 7.1 & 0.46 & 99.750 \\
\hline 26.071070 & 44.500660 & 9.3 & 34.7 & 6.7 & 0.37 & 99.650 \\
\hline 26.071077 & 44.500671 & 9.6 & 71.6 & 6.8 & 0.41 & 99.600 \\
\hline 26.071083 & 44.500679 & 8.2 & 6.5 & 7.5 & 0.44 & 99.500 \\
\hline 26.071091 & 44.500687 & 10.6 & 15.5 & 6.9 & 0.42 & 99.250 \\
\hline 26.071100 & 44.500694 & 9.0 & 11.0 & 7.3 & 0.42 & 99.000 \\
\hline 26.071112 & 44.500702 & 10.3 & 11.8 & 7.0 & 0.41 & 98.850 \\
\hline 26.071121 & 44.500713 & 8.5 & 12.8 & 7.2 & 0.42 & 98.650 \\
\hline 26.071135 & 44.500721 & 7.3 & 8.0 & 7.2 & 0.43 & 98.550 \\
\hline 26.071148 & 44.500729 & 9.1 & 4.6 & 6.9 & 0.38 & 98.550 \\
\hline
\end{tabular}

The mean value and standard deviation for the analyzed parameters were calculated mathematically using the Excell program, table 2.

Following the processing of the experimental data obtained within the Inma Bucuresti polygon on the wheat crop (variety CXV), the following graphs were obtained, which represent the influence of the analyzed parameters EC Surface, EC Deep and Ph respectively on the productivity of the cereal crop. 
Mean value and standard deviation for the analyzed parameters

\begin{tabular}{|c|c|c|c|c|}
\hline Statistics & $\begin{array}{c}\mathbf{E C}_{\text {SURFACE }} \\
\mathbf{m S}^{-1} \mathbf{m}^{-\mathbf{1}}\end{array}$ & $\begin{array}{c}\mathbf{E C}_{\text {DEEP }} \\
\mathbf{m S}^{-\mathbf{- 1}}\end{array}$ & $\mathbf{p h}$ & $\begin{array}{c}\text { Yield } \\
\mathbf{k g} \cdot \mathbf{m}^{-2}\end{array}$ \\
\hline Average & 7.61 & 26.91 & 7.6 & 0.43 \\
\hline Standard deviation & 2.91 & 41.48 & 0.48 & 0.02 \\
\hline
\end{tabular}

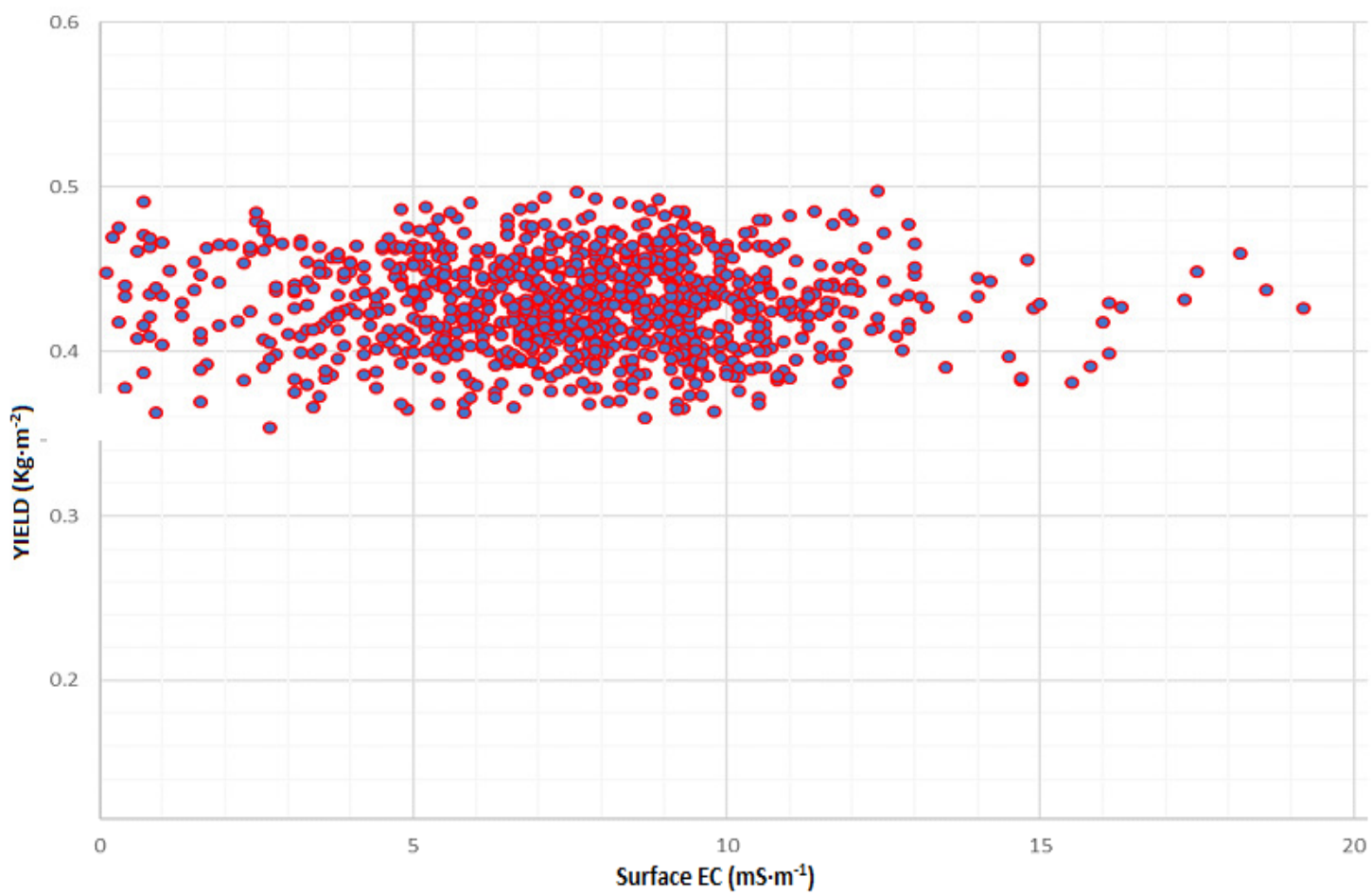

Fig. 3. Graph of $\mathbf{E C}$ Surface influence on cereal productivity

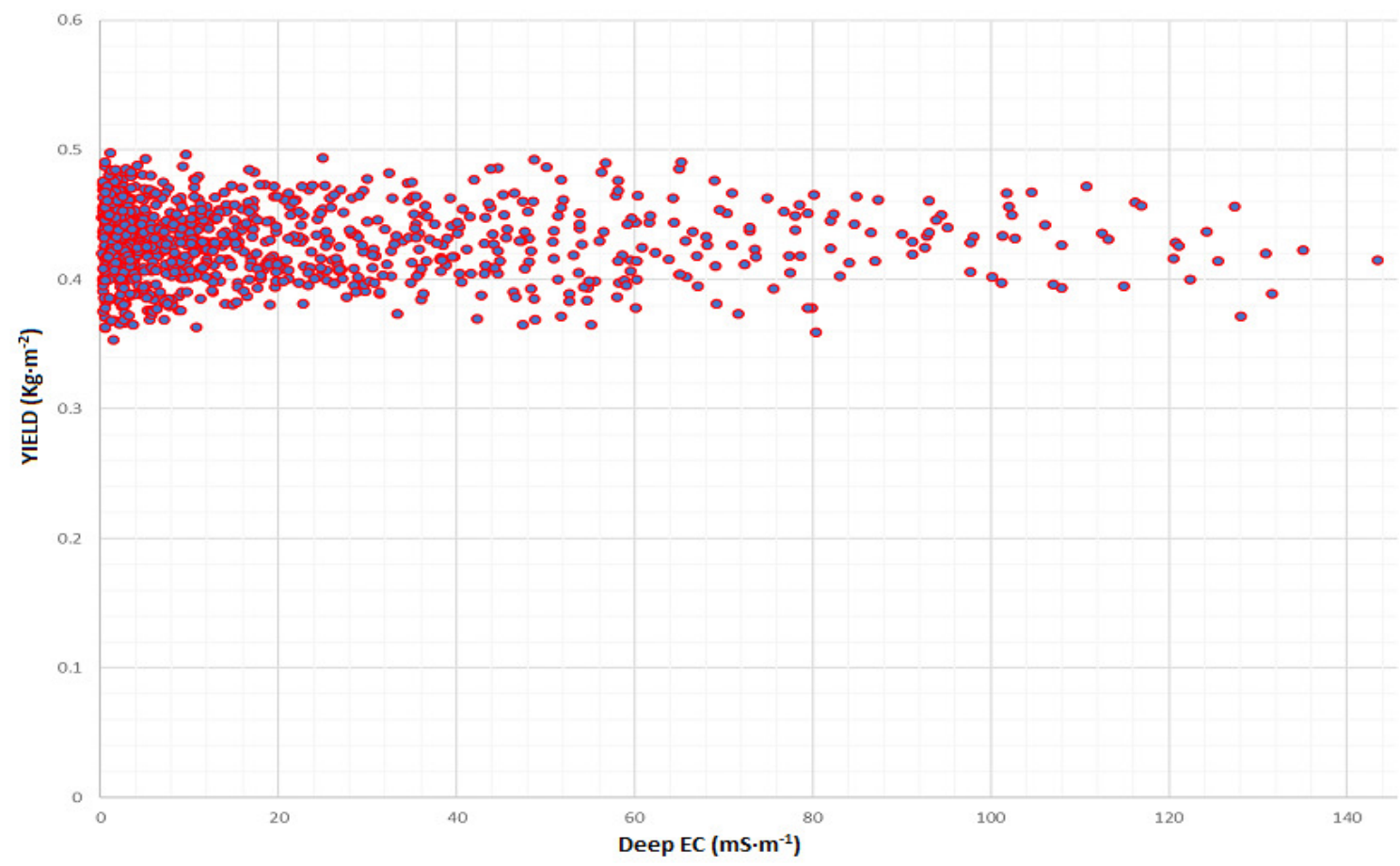

Fig. 4. Graph of $\mathbf{E C}_{\text {Deep }}$ influence on cereal productivity 


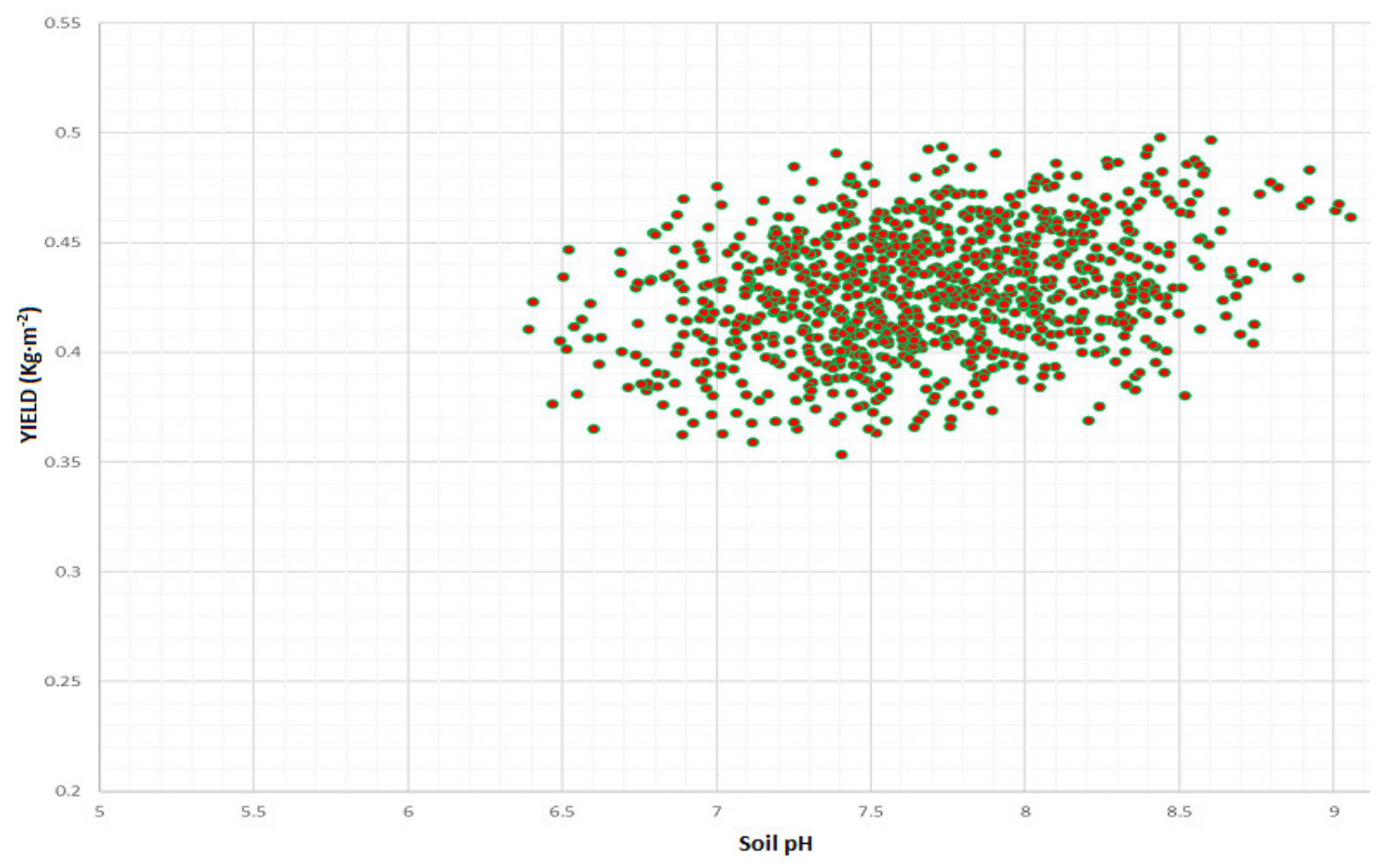

Fig. 5. Graph of soil ph influence on cereal productivity

\section{Conclusions}

Following the analysis of the experimental data, the following conclusions can be drawn:

1. The wheat production obtained is acceptable being $4285 \mathrm{~kg} \cdot \mathrm{h}^{-1} \mathrm{a}$, provided that the fertilization conditions were the standard ones, the crop being not irrigated in addition to the natural contribution of water brought by rainfall in the form of snow and rain.

2. $E_{\text {Surface }}$ recorded an average value of $7.61 \mathrm{mS} \cdot \mathrm{m}^{-1}$ with a weight of over $65 \%$ of the values in the range $5-10 \mathrm{mS} \cdot \mathrm{m}^{-1}$, with an average productivity of $0.4-0.5 \mathrm{~kg} \cdot \mathrm{m}^{-2}$.

3. $\mathrm{EC}_{\mathrm{DEEP}}$ recorded an average value of $26.91 \mathrm{mS} \cdot \mathrm{m}^{-1}$ with a weight of over $60 \%$ of the values in the range $0-20 \mathrm{mS} \cdot \mathrm{m}^{-1}$, with an average productivity of $0.35-0.5 \mathrm{~kg} \cdot \mathrm{m}^{-2}$.

4. The soil $\mathrm{pH}$ recorded an average value of 7.6. It shows a basic alkalinity with values up to 9.2 with a corresponding productivity.

\section{Acknowledgements}

This work was supported by the UEFISCDI, Project/contract No. 9PCCDI/09.03.2018: "COMPLEX SYSTEM FOR INTEGRATED VALUATION OF SOME AGRICULTURAL SPECIES WITH ENERGY AND FOOD POTENTIAL", and through a grant on Programme 1 - Development of the national research-development system, subprogramme 1.2 - Institutional performance - Projects for financing excellence in RDI, contract No. 16 PFE.

\section{References}

[1] Matache M., Voicea I., Vlăduţ V., Pirnă I., Bungescu S., Chirilă C. Experimental models of electro-conductivity and productivity agricultural maps for the cambic chernozem soil. WSEAS International Conferences on Energy, Environment, Economics, Devices, Systems, Communications, Computers (IAASAT) - Computational Engineering in Systems Applications,

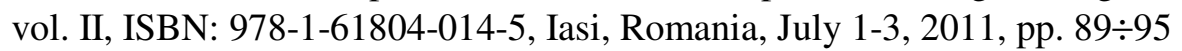

[2] Husson O., Brunet A., Babre D., Charpentier H., Durand M. Conservation Agriculture systems alter the electrical characteristics (Eh, pH and EC) of four soil types in France. Soil and Tillage Research , vol. 176, March 2018, pp. 57-68. 
[3] Knadel M., Thomsen A., Schelde K. Soil organic carbon and particle sizes mapping using visNIR, EC and temperature mobile sensor platform. Computers and Electronics in Agriculture, vol. 114, June 2015, pp. 134-144.

[4] Howard P., Soil protection and soil quality assessment in the EC. Science of The Total Environment, vol. 129, Issues 1-2, 16 February 1993, pp. 219-239.

[5] Zhanga K., Chenc L.,Philip C., Jianming Xu., Yu L. Interactive effects of soil pH and substrate quality on microbial utilization. European Journal of Soil Biology, vol. 96, January-February 2020, pp. 103-151.

[6] Arie N. Methodologies and the Practical Aspects of the Bulk Soil EC $\left(\sigma_{\mathrm{a}}\right)$-Soil Solution EC $\left(\sigma_{\mathrm{w}}\right)$ Relations. Advances in Agronomy, vol. 88, 2005, pp. 273-312.

[7] Hengl D. Chapter 20 Soil Mapping Applications. Developments in Soil Science, vol. 2009, pp. 461-479.

[8] DaliakopoulosaI N., Tsanisab K., Koutroulisa A., Kourgialasa N., Varouchakis A. The threat of soil salinity: A European scale review. Science of The Total Environment, vol. 573, 15 December 2016, pp.727-739.

[9] Corwin D.L., S.M. Lesch.. Application of soil electrical conductivity precision agriculture: Theory. Principals, and guidelines, 2003, Agron. J. 95, pp. 455-47.

[10]Lund E.D., Chris C., Drummond.P. Practical applications of soilelectrical conductivity mapping, Proc. 2nd European Conference on Precision Agriculture, 11 - 15 July 1999.

[11] Amin M., Aimrun W., Eltaib S., Chan C. Spatial soil variability mapping using electrical conductivity senzor for precision farming of rice. International Journal of Engineering and Technology, Vol. 1, No. 1, 2004, pp. 47 - 57.

[12] Rhoades J.D., Corwin, D.L. Determining Soil Electrical Conductivity-depth Relations Using an Inductive Electromagnetic Conductivity Meter, Soil ScienceSociety of America Journal, 45, pp. 255-260; 